\title{
Швандерова А.P. \\ Опыт применения дистанционных технологий в формировании социально - когнитивных способностей студентов
}

Ростовский филиал ФГБОУ ВО «Российский государственный университет правосудия

doi: $10.18411 / s r-10-04-2021-63$

(Россия, Ростов-на -Дону)

\section{Аннотация}

Статья посвящена опыту применения инновационных технологий в формировании социально -когнитивных способностей студентов в учебном процессе в условиях пандемии Covid-2019. Автор привлекает внимание к самой серьезной, на его взгляд, проблеме дистанционного обучения - невозможность «живого», непосредственного вовлечения студентов в образовательную среду, являющуюся необходимым условием социализации как процесса взаимодействия индивида и социума, усвоения индивидом социальных и культурных норм, различных социальных ролей.

Ключевые слова: дистанционное обучение. «виртуальная аудитория», пандемия, когнитивные способности, социализированный индивид. Социальный интеллект.

\section{Abstract}

The article is devoted to the experience of using innovative technologies in the formation of students ' social and cognitive abilities in the educational process in the context of the Covid-2019 pandemic. The author draws attention to the most serious, in his opinion, problem of distance learning - the impossibility of "live", direct involvement of students in the educational environment, which is a necessary condition for socialization as a process of interaction between the individual and society, the individual's assimilation of social and cultural norms, various social roles.

Keywords: distance learning. "virtual audience", pandemic, cognitive abilities, socialized individual, social intelligence.

На протяжении всей своей истории человек стремится к совершенствованию своих знаний и умений. Сегодня это стремление становится особенно актуальным, поскольку мир современного человека - это очень сложная социальная социотехническая система. И чтобы выжить в ней, необходим очень высокий уровень развития социально- когнитивных способностей - развитое аналитическое мышление, специальные, в том числе технические навыки, эмоциональный интеллект социализированной личности - способность работать в команде, навыки межличностного взаимодействия и т.д. Именно поэтому современное образование все большее внимание уделяет преподаванию социальных дисциплин, распространению знаний о и правопорядке с применением информационных технологий и инновационных методик. В этой связи представляется неоднозначным, но интересным ставшее особо востребованным в условиях пандемии Covid-2019 дистанционное обучение, основанное на информационных технологиях, позволяющих преподавателю и студенту, независимо от того, на каком расстоянии они находятся друг от друга, и от санпандемических условий, продолжать процесс обучения.

При этом необходимо отметить, что дистанционное обучение - вовсе не новая образовательная технология в образовании. Так, уже XX век знал и практиковал заочное (на дистанции) обучение, применяющее все имеющиеся средства коммуникации - почту, радио, телевидение. 
В конце XX - начале XXI века началась эпоха информационных технологий, сети Интернет, и это, безусловно, вывело дистанционное обучение на совершенно иной качественный уровень. Например, в преподавании дисциплин «История отечественного государства и права», «Теория государства и права» на факультете подготовки специалистов судебной системы сегодня применяются следующие формы дистанционного обучения с применением информационных технологий:

1) использование информации из сети Интернет в качестве дополнительных материалов по изучаемым темам. Поиск студенты осуществляют по конкретным адресам, рекомендованным преподавателем, например, юридическая библиотека и др.;

2) комбинированный путь, когда происходит использование информации из Интернета в качестве дополнительного материала по изучаемым темам, то есть студентам предоставляется список ссылок на электронные ресурсы, отобранные преподавателем, но в дополнение студенты самостоятельно осуществляют поиск необходимой информации при помощи поисковых систем;

3) использование информации из Интернета в качестве дополнительных материалов по изучаемым темам, при этом поиск осуществляется студентами самостоятельно при помощи различных поисковых систем (Yandex, Rambler,Google и т.д.); поиск информации в информационно правовых системах ГАРАНТ и КонсультантПлюс;

4) специально организованная переписка студентов с преподавателем по электронной почте - оперативное консультирование в удобное для участников переписки время при подготовке выступлений на миниконференциях, «круглых столах», студенческих научно-практических, исследовательских конференциях.

Год пандемии принес уникальный опыт - в силу сложившихся обстоятельств и невозможности реализации учебного процесса в режиме очного обучения особенно востребованной стала «виртуальная учебная аудитория» - виртуальная среда, с помощью которой удается сформировать и длительное время удерживать единство информационного пространства учебного заведения.

Приведём в качестве примера проведение в виртуальной аудитории учебной дискуссии «Дерево решений» - метод всех возможных вариантов.

Он используется для рационализации процесса принятия решений в ситуации, когда невозможно дать простой и однозначный ответ на поставленную задачу. Кроме того, эта методика применяется при анализе конкретной сложной (новой) ситуации и помогает достичь полного понимания причин, которые привели к выдвижению той или иной теории.

Например, проблема: изучение норманской и антинорманнской теории зарождения российской государственности.

Студенты, получив задание от преподавателя, детально анализируют все возможные варианты ответов, выписывают в колонки преимущества и недостатки каждого из них, а также те познавательные проблемы, которые они могут за собой повлечь. При этом очевидно, что студенты самостоятельно должны найти базовую информацию, обратившись к историческим документам, научной, учебной литературе. В ходе работы студенты заполняют предложенную таблицу, записывая в колонки преимущества и каждого варианта, принимают решение по проблеме.

Итоги своей работы высылают преподавателю, который в данной дискуссии является информационно-аналитическим центром. Преподаватель-координатор призван сравнить результаты, помочь разобраться, почему в том или ином случае приняты одинаковые или различные решения, ответить на вопросы и помочь в анализе информации. 
Еще один пример. Хорошо известная и популярная форма проведения интерактивных занятий - «мозговой штурм» - эффективный метод коллективного обсуждения, поиск решения в котором осуществляется путём свободного выражения мнения всех участников. Применение метода «мозгового штурма» заставляет работать и весь багаж знаний, имеющийся у студентов, и их воображение Практика показывает, что за несколько минут можно получить несколько десятков идей, например, по теме «Способы преодоления коллизий и устранения коллизий в праве». При этом, конечно же, количество идей не является самоцелью, а лишь служит основой для выработки наиболее разумного решения.

В итоге «виртуальная аудитория» подтвердила применимость всех форм обучения: и пассивной, и активной, и даже интерактивной. Конечно, учебный процесс значительно усложнился, как для преподавателей, так и для студентов- затрачиваемое на подготовку к занятиям время выросло в разы, но и научил многому: дал возможность увидеть несомненные плюсы и, увы, минусы дистанционной формы обучения. Так, названные формы проведения занятий в виртуальной аудитории, несомненно, являются весьма эффективной формой обучения, во-первых, потому, что дают возможность проводить обучение независимо от неблагоприятных социальных условий, состояния здоровья и даже географического положения; во-вторых, осуществляется необходимое в процессе обучения взаимодействие преподавателя и студентов, студентов между собой учащихся и учащихся между собой, то есть включены и действуют все составляющие учебный процесс компоненты: цели, содержание, методы, организационные формы, средства обучения; студенты ищут и анализируют информацию; развивают навыки критического мышления и т.д.; втретьих, применяются инновационные технологии с использованием Интернетвозможностей и интерактивных методов обучения.

С другой стороны, и студенты, и преподаватели сталкиваются с достаточно серьезными проблемами как технического характера - неустойчивая интернет-связь, случающиеся перебои в электроснабжении и т.д., так и с необходимостью проводить за компьютером немало времени практически без движения, что. безусловно, не добавляет здоровья участникам учебного процесса. Названные проблемы известны и широко обсуждаются и педагогами, и медицинскими работниками. И техническими специалистами. И даже политиками разного уровня.

Однако самая серьезная проблема, на наш взгляд, заключается в том, что «виртуальная аудитория», развивая аналитическое мышление, специальные, в том числе технические навыки, исключает живое общение, являющееся необходимым условием соџиализаџии как процесса взаимодействия индивида и социума, усвоения индивидом социальных и культурных норм, различных социальных ролей. А высокий интеллектуальный уровень и обилие технических навыков являются, хотя и, безусловно, необходимыми, но не достаточными условиями социализации личности. Они способствуют социальному развитию, но не заменяют его. Более того, история человечества знает немало примеров того, как даже незаурядный интеллект может «уживаться» с социальной наивностью и даже социальной слепотой и безответственностью - достаточно вспомнить известный «Манхэттенский проект», объединивший 6000 выдающихся интеллектуалов и закончившийся ядерной бомбардировкой японских городов и гибелью миллионов мирных людей...

Личность, характеризующаяся богатством социальных и духовных качеств, включенная и самостоятельно включающаяся в разнообразные общественные отношения, обладающая когнитивными способностями - умением сознательно обрабатывать поступающую информацию, преобразовывать ее в знания, хранить и использовать накопленный социумом опыт в практической деятельности. Сами по себе знания, какими бы объемными и разносторонними они ни были, не могут 
сформировать личность, ее убеждения, ценности, мировоззрение, формируется только в процессе социализации. В свое время выдающийся советский психолог Лев Семенович Выготский охарактеризовал личность как социализированного индивида, самостоятельную целостную психическую систему, которая выполняет определенные функции, основными из которых являются - творческое освоение общественного опыта и включение человека в систему общественных отношений. Все стороны личности обнаруживаются только в деятельности и в отношениях с другими людьми. Личность существует, проявляется и формируется в деятельности и общении, под непосредственным... влиянием ближайшего окружения, микросреды...

Значительная роль в организации такой уникальной микросреды принадлежит образованию - важнейшему институту социализации, как раз и обеспечивающему условия для сочетания знаний с эмоциональными, «живыми» межличностными отношениями, формированию особой когнитивной способности - социального интеллекта, необходимого для эффективного межличностного взаимодействия и успешной социальной адаптации. Современному сложному, постоянно развивающемуся обществу нужна именно такая самостоятельная личность, потому что несамостоятельный, интеллектуально и социально неразвитый человек не в состоянии правильно понять и оценить стремительные социальные изменения, боится их, и в результате вступает в конфликт и с самим собой, и с социумом. В такой ситуации становится возможным манипулирование сознанием несамостоятельной личности, ее выбором социальных ролей и моделей поведения с помощью лживой информации и деструктивного общения со стороны всевозможных псевдоагентов социализации в лице доморощенных недалеких блогеров и им подобных.

Таким образом, дистанционное образование, утвердив свою значимость в экстремальных условиях пандемии, обрело право на существование лишь как дополнение к основному, проводящемуся очно и в режиме реального времени. Опыт пандемии оказался очень важным в процессе развития различных альтернативных методик обучения и доказал - при всем развитии технического прогресса необходимость традиционных методов и форм образования, основой которого является прямое « живое» взаимодействие преподавателя и студентов.

$$
\text { *** }
$$

1. Выготский Л. С. Мышление и речь. М.-Л.: Соцэкгиз, 1934.

2. Мудрик, А. В. Социальная педагогика .учеб. для студ. пед. вузов / Под ред. В.А. Сластенина. - 3-е изд., испр. и доп. - М.: Академия, 2000.

3. Швандерова А.Р. Инновации в системе образования - новое или незабытое старое? // Материалы международной научно практической конференции «Современное состояние и приоритетные напрвления развития аграрной экономики и образования». ДОНГАУ, 7 февраля 2019 (РИНЦ).

\section{Шоидарвозова Г.С. \\ Инновационные подходы в образовательном процессе на примере Хорогского государственного университета}

Хорогский государственный университет имени М. Назаршоева

doi: $10.18411 /$ sr-10-04-2021-64

(Таджикистан, Хорог)

\section{Аннотация}

Мировая тенденция сложилась таким образом, что основная роль отводиться электронным ресурсам. Поэтому в данной статье рассматривается проблемы внедрения электронно-образовательных ресурсов в учебный процесс на примере Хорогского государственного университета. Кроме того ведущая роль в статье отводиться педагогу, как основного субъекта для реализации программы внедрения 